Please cite this article as:

Colombo G, Dell'Era C, Frattini F and Landoni P (2016).

Understanding Virtual Knowledge Brokers and their Differences with Traditional Ones. International Journal of Innovation Management, Vol. 20, No.1.

(DOI: 10.1142/S1363919616500158) 


\section{UNDERSTANDING VIRTUAL KNOWLEDGE BROKERS AND THEIR DIFFERENCES WITH TRADITIONAL ONES}

\section{Gabriele COLOMBO}

Department of Management, Economics and Industrial Engineering, Politecnico di Milano - Piazza L. da Vinci, 3220133 Milano Italy

Tel: +390223992798

Fax: +390223994083

gabriele.colombo@polimi.it

Claudio DELL'ERA (Corresponding author)

Department of Management, Economics and Industrial Engineering, Politecnico di Milano - Piazza L. da Vinci, 3220133 Milano Italy

Tel: +3902 23992798

Fax: +3902 23994083

claudio.dellera@polimi.it

\section{Federico FRATTINI}

Department of Management, Economics and Industrial Engineering, Politecnico di Milano - Piazza L. da Vinci, 3220133 Milano Italy

Tel: +390223992796

Fax: +3902 23994083

federico.frattini@polimi.it

\section{Paolo LANDONI}

Department of Management, Economics and Industrial Engineering, Politecnico di Milano - Piazza L. da Vinci, 3220133 Milano Italy

Tel: +3902 23993973

Fax: +3902 23994083

paolo.landoni@polimi.it

Keywords: NPD Service Providers, Web-based Intermediaries, Knowledge Brokers, Brokering process, Competitions 


\title{
UNDERSTANDING VIRTUAL KNOWLEDGE BROKERS AND THEIR DIFFERENCES WITH TRADITIONAL ONES
}

\begin{abstract}
Virtual knowledge brokers help their clients solve challenging innovation problems by leveraging the diverse knowledge basis of vast communities of solvers. Despite the increasing diffusion of virtual knowledge brokers, no efforts have been done so far to investigate the anatomy of the brokering process they follow to deliver a service to their clients. This paper analyses how virtual knowledge brokers go through the four macro-phases of the brokering process (i.e. access, learning, linking and implemenation) and points out the main differences with traditional brokers. The research is based on a multiple case study involving two Italian virtual knowledge brokers. The analysis suggests that virtual knowledge brokers are characterized by a stronger ability to access different knowledge domains in comparison with traditional knowledge brokers. However, virtual knowledge brokers are less effective in the learning and linking phases of the process, due to the distance that separates solvers and clients and the lack of communication and interaction between solvers. Starting from these insights, the ability of virtual and traditional knowledge brokers to solve different types of innovation problems is analyzed. The paper contains also a discussion of the managerial implications of this study, especially for those firms that has to select the best knowledge brokers with which to collaborate.
\end{abstract}

Key Words: Knowledge Brokers, Brokering Process, Competitions, New Product Development, Intermediaries. 


\section{INTRODUCTION}

In order to remain competitive in the fast changing and unpredictable business environment, firms have to innovate continuously their products and services (Cooper and Kleinschmidt, 2003). In this context, knowledge brokers can strengthen a firm's innovative capability by decreasing new product development cost, speeding up development time as well as enabling offering new product attributes (Tran et al., 2011; Bolisani and Scarso, 2009). This because they provide their clients with different services, such as technology and market scouting, concept generation, design, engineering, testing and prototyping (Chiaroni et al., 2008). Knowledge brokers bridge knowledge "from where it is known to where it is not" (Hargadon, 1998: 2), thus supporting innovation activities by favouring the original recombination of existing pieces of knowledge (Henderson and Clark 1990; Kogut and Zander 1992; Grant 1996).

In the last years, besides traditional knowledge brokers like IDEO (www.ideo.com) and Continuum (www.continuuminnovation.com), a new class of knowledge brokers is emerging. They leverage the power of the web to allow firms to connect and recombine highly dispersed pieces of knowledge, by accessing the knowledge of single individuals with professional experience in heterogeneous domains, living and working all over the world. These knowledge brokers, such as 99Designs (www.99designs.com), Ponoko (www.ponoko.com), Design Contest (www.designcontest.com), are defined virtual knowledge brokers in the remainder of the paper. They connect firms that want to innovate (the seekers), with creative people (the solvers), operating in different industries all over the world. According to Nielsen et al. (2013) online intermediaries' activities in the EU contributed around $€ 430$ billion to the GDP of the EU27 in 2012. This is comprised of a direct GDP contribution of $€ 220$ billion and a long-term indirect GDP contribution due to the productivity impact of intermediaries on other firms of $€ 210$ billion. The importance of virtual knowledge brokers has been recognised also in the existing literature (e.g., Jeppesen and Lakhani, 2010; Terwiesch and Xu, 2008; Colombo et al., 2013). Virtual knowledge brokers can have different characteristics (Colombo et al., 2013; Colombo et al., 2015; Chesbrough, 2006), as they can connect seekers with a vast community of solvers in different ways. Some of them enable companies to broadcast their innovation problems to large communities of solvers in order to attract several solutions to the problems. Instead other web-based intermediaries support companies in the identification of the best solvers with which to collaborate. this paper we focus our attention on virtual knowledge brokers that run competitions (Jeppesen and Lakhani, 2010; Terwiesch and Xu, 2008; Boudreau et al., 2011; Muhdi et al., 2011). This because competition is a very dissimilar way, compared to the services offered by traditional knowledge brokers, to support firms in accessing new knowledge domains and to bring knowledge from where it is known to where it is not. In a competition, the seeker broadcasts its innovation 
problems, e.g., the brief for the development of a new product, to a large crowd of solvers and then provides an award to the solver that has developed the best solution, e.g., the best concept for a new product. Thus, virtual knowledge brokers that run competitions enable seekers to access different knowledge domains by exposing them to the power and creativity of communities of individuals with educational and professional experience in different geographical and disciplinary areas. Therefore, in the remainder of the paper we refer to virtual knowledge brokers focusing in particular on virtual knowledge brokers that run competitions.

While existing studies have mostly focused on the ability of virtual knowledge brokers to access alternative sources of knowledge (Jeppesen and Lakhani 2010; Terwiesch and Xu 2008; Boudreau et al. 2011; Verona et al., 2006), very little is known about the process through which they recombine new pieces of knowledge in a novel way. Furthermore, the advantages and disadvantages provided by virtual knowledge brokers in comparison to the traditional ones are mainly missed in the existing literature and this comparison can provide interesting managerial guidelines. The study presented in this paper wants to make a step further in filling these gaps, by answering these questions:

(i) How do virtual knowledge brokers (that run competitions) organise their brokering process?

(ii) How does the brokering process followed by virtual knowledge brokers (that run competitions) differ from the process used by traditional knowledge brokers?

This paper answers the two research questions by discussing the findings of an exploratory multiple case study, which involved two Italian virtual knowledge brokers, and by comparing the process they follow to deliver their services with the one adopted by traditional knowledge brokers, which has been largely discussed in the literature (see, e.g., Hargadon, 1998). The paper is organised as follows. In the next section, we provide a review of the literature on knowledge brokers. Afterwards, we illustrate our theoretical framework and the methodology we followed in the empirical analysis. In section five, we present the results of the multiple case study. Finally, we discuss the theoretical and managerial implications of the study.

\section{LITERATURE REVIEW}

Knowledge brokers can "come into different forms" (Chesbrough 2006: 140); they can help "to provide information about potential collaborators; to broker a transaction between two or more parties; act as a mediator, or go-between, bodies or organizations that are already collaborating; and help find advice, funding and support for the innovation outcomes of such collaborations" (Howells, 
2006: 720). Knowledge brokers can be conceived as a particular type of innovation intermediary that add value to the client's new product development (NPD) processes by playing a brokering role, i.e. by bringing knowledge "from where it is known to where it is not" (Hargadon, 1998: 2). Knowledge brokers acquire different pieces of knowledge by working with clients operating in several industries and are able to recombine such knowledge into new products and services (Hargadon, 1998). In particular, knowledge brokers benefit from their unique network position and their role as broker between parties otherwise disconnected (Hargadon and Sutton, 1997). Using the concepts of social network theory, knowledge brokers leverage the fact of being broker in a network rich of structural holes, defined as "gaps in information flows between alters linked to the same ego but not linked to each other" (Ahuja, 2000: 431). Accordingly, Doloreux and Muller (2007) suggest that the perception of knowledge brokers has evolved from an early characterisation as providers of specific information for their clients (Wood et al., 1993), to the recent identification as key nodes of knowledge-related networks, which can trigger and reinforce processes of knowledge transformation and assimilation in client firms. Furthermore, the ability of knowledge brokers to support a firm's innovation activities depends also on how such intermediaries deliver their brokering service. In this vein, Hargadon and Sutton (1997: 717) claim that a broker ability "depends on both its network position as a broker and on an organizational memory that allows it to acquire, retain, and retrieve new combinations of information obtained through such a position." This has led scholars to investigate the process through which knowledge brokers acquire and recombine different pieces of knowledge in a novel way (Hargadon and Sutton, 1997; Hargadon and Sutton 2000; Sutton 2002). In particular four main activities in the knowledge brokering process have been identified:

- Access activities aimed at connecting a range of otherwise disconnected industries;

- Learning activities that allow to collect and store knowledge that can be exploited during future projects;

- Linking activities aimed at highlighting non-obvious similarities between two things that appear to be dissimilar;

- Implementation activities that allow to transform innovative ideas into real products.

In the last years, the evolution and the improvement of internet technologies have given rise to a new class of knowledge brokers, defined as virtual knowledge brokers (Verona et al. 2006). These intermediaries connect firms with innovation needs, called seekers, with people all over the world characterized by different knowledge backgrounds, called solvers. In other words, virtual knowledge brokers play a brokering role by directly connecting firms with different pieces of knowledge (Jeppesen and Lakhani, 2010; Terwiesch and Xu, 2008; Boudreau et al., 2011) and benefit from their unique market position to generate innovations (Verona et al. 2006). In this vein, Verona et al (2006) 
analyze the benefits for virtual knowledge brokers to leverage internet technologies in order to integrate and recombine different pieces of knowledge. Literature recognizes that virtual knowledge brokers ability to identify relevant solutions to firms' innovation problems is positively impacted by increasing the number of solvers that participate to the solution of a specific problem (Terwiesch and $\mathrm{Xu}, 2008$ ), thanks to the possibility to include some unexpected solutions coming from unknown knowledge domains (Jeppesen and Lakhani, 2010).

Despite research has acknowledge the importance of virtual knowledge brokers in helping firms solve their innovation problems, there is a lack of studies investigating the process followed by virtual knowledge brokers to deliver their services. To fill this gap, a comparison between the brokering process followed by virtual and traditional knowledge brokers can be useful, as it can unearth similarities and differences rich of theoretical and empirical implications. In the next section, we develop the theoretical framework that was used to support our empirical analysis.

\section{THEORETICAL FRAMEWORK}

We ground our theoretical framework in the model by Hargadon (1998). Although this model has been developed by making reference to traditional knowledge brokers, it is useful because it offers a macro-categorization of the phases the brokering process goes through and along which the differences between virtual and traditional brokers can be highlighted. As previously mentioned, Hargadon (1998) identifies four different activities through which knowledge brokers offer their service, namely access, learning, linking and implementation. In the next paragraphs, we summarize what is known about these four phases of the brokering process conducted by traditional knowledge brokers. This description will be compared with the characteristics of the brokering process followed by virtual knowledge brokers as it will emerge from our exploratory empirical study.

Regarding the first phase of the process, access to a range of otherwise disconnected industries represents a critical step in the innovation strategies of knowledge brokers, which profit from enabling the flow of resources from where they are plentiful to where they are scarce (Hargadon, 1998). Building a network requires maximizing the proportion of bridges (i.e., non-redundant contacts) to total contacts in the network (Burt, 1992). In fact, innovation is significantly affected by the diversity of its direct contacts, whose number is relevant only to the extent that it increases the probability of network diversity. Several studies on networks suggest that a firm's portfolio of partners may be as influential as the dyadic characteristics of those alliances (Gulati, 1998). 
"Working with companies in such dissimilar industries as medical instruments, furniture, toys and computers has given us a broad view of the last technologies available and has taught us how to do quality product development and how to do it quickly and efficiently."

Dave Kelly, past CEO of IDEO (Hargadon, 1998)

Concerning the second macro-phase of the process, it is necessary to highlight that innovation mainly involves creating new solutions by adopting and adapting existing solutions from elsewhere. For this reason, knowledge brokers invest in learning activities that allow them to collect and store knowledge that can be exploited during future projects. Considering that many valuable solutions are already on the market, embodied in competitors' products or similar products in other industries, knowledge brokers use to develop activities such as simulation, observation and benchmarking in order to generate knowledge that can be used immediately or in later projects. Several knowledge brokers call the initial phase of their innovation projects "alignment and learning" (Colombo et al., 2011). The aim of this phase is twofold. On the one hand, they gather and interpret, through several face-to-face, personal contacts with the client's managers, the client's needs and diagnoses its organizational culture (alignment). This task is of paramount importance to refine the original brief of the project and agree on the collaboration both for the knowledge brokers and its client. On the other hand, the characteristics of the market where the client sells its products are thoroughly investigated by the knowledge brokers, with the aim to identify useful insights for the development of the new product learning). In order to enrich the exploitable knowledge base, knowledge brokers use to develop "internal" projects called "meta-projects" or "evocative projects" (Dell'Era et al., 2015): their nature is really explorative because they have to face less constraints, for the same reason they are more radical in comparison to "traditional" projects, and they aim at developing new scenarios and concepts.

Moving to the third phase of the model, Hargadon (1998) argues that knowledge brokers base the linking activity on analogic thinking: "analogies highlight non-obvious similarities between two things that appear to be dissimilar, and analogic thinking occurs when an individual, facing a novel problem, sees non-obvious similarities in other problems he or she has faced in the past" (Hargadon, 1998: 219). In collaborating with heterogeneous partners, a firm can not only increase its recombination possibilities, but also recognize opportunities ahead of competitors. Collaborations with heterogeneous partners may lead to constructive conflict, increasing a firm's problem-solving capabilities and approaching new opportunities through new frameworks (Haunschild and Sullivan, 
2002). Exposure to heterogeneous knowledge should improve managers' innovation ability and the variety of knowledge to which a manager is exposed has a positive impact on performance (Rodan and Galunic, 2004). Knowledge brokers use different techniques in order to facilitate the linking activity, such as dedicating rooms to expose prototypes and products developed during past projects in order to embody their knowledge, facilitating intriguing connections and stimulate the organization's ability to think out-of-the-box.

The last macro-phase identified by Hargadon (1998) is implementation and it consists in transforming innovative ideas into real products. Knowledge brokers, since the initial stage of the innovation project, realize preliminary embodiments of the final products and services (e.g., sketches, storyboards, prototypes). By doing so, they are able to concretize the knowledge developed during the previous activities. In order to continually generate new knowledge throughout the innovation process, knowledge brokers rely heavily on experimentation. The process starts with a concept draft that is immediately embedded into a prototype (that can be either analytical or physical). The prototype is tested involving the final user in order to generate early feedback that the designer can use to further develop the concept and detail the architecture. Sketches and prototypes aim at creating new knowledge in order to take important decisions.

Table 1 summarizes the macro-phases the knowledge brokering process goes through, according to the model developed by Hargadoon (1998).

Insert Table 1 here

Following this model, through the exploratory empirical research presented in the following section we studied how virtual knowledge brokers go through the access, learning, linking and implementation phases of the brokering process and, by doing do, support the innovation process of their clients. The characteristics of the virtual brokering process that emerge from the empirical analysis are compared with the anatomy of the process described in existing research and implemented by traditional knowledge brokers.

\section{METHODOLOGY}

Given the aim of the investigation and our conceptual starting points, we adopted an exploratory approach in our empirical analysis. In particular, we conducted a multiple case study by examining the brokering process followed by two virtual knowledge brokers. Case studies allow studying 
complex phenomena, embedded in their context, to collect detailed and rich data and are longitudinal by default (Easton, 1998; Yin, 2003). Moreover, they are particularly suited to answer to "how" research questions and for exploratory research (Yin, 2003). The selection of the two cases was based on the combination of theoretical interest and convenience sampling (Siggelkow, 2007; Dubois and Gadde, 2002) and it followed these steps. First, a preliminary list of virtual knowledge brokers was created through the screening of different sources of information, following a procedure similar to the one described in Chesbrough and Crowther (2006). Two main sources of information were used to this aim: (i) existing literature on the topic (e.g., Chesbrough 2006; Boudreau et al. 2009; Lichtenthaler and Ernst 2008a; 2008b; Muhdi et al., 2011); (ii) web searches relying both on generic web-search engines (e.g., Google) and on the virtual knowledge brokers search and aggregator engine Donanza (www.donanza.com). This process allowed us to identify a list of 15 virtual knowledge brokers that run competitions. Afterwards, we collected information about these 15 brokers by searching into their websites and publicly available information. This information was used to select the virtual knowledge brokers on which we should focus our analysis, by considering the following criteria: (i) we selected those virtual knowledge brokers for which the brokering process is easily observable (Eisenhardt, 1989); (ii) we considered those virtual knowledge brokers that focus on new product development problems only, similarly with traditional knowledge brokers. Put differently, we excluded from the analysis those virtual knowledge brokers that are active on technical and R\&D problems, such as Innocentive. Again, this was done to ease the observation of the knowledge brokering process, which is the particular focus of our analysis; (iii) we used a convenience sampling logic by choosing Italian knowledge brokers, in order to increase the possibility for the authors to conduct an in-depth analysis of the case, through direct, face-to-face interviews, in the native language of the authors and interviewees (i.e., Italian). After this selection process, we came up with two virtual knowledge brokers which represented the sample of our exploratory analysis. Table 2 provide a brief description of these two brokers.

Insert Table 2 here

The data about the two cases were collected mainly through face-to-face interviews, following a semistructured interview protocol which mirrored closely the structure of our theoretical framework (see Figure 1). Our open-ended questions were designed to capture the anatomy of the brokering process undertaken by the virtual knowledge brokers throughout the four phases in which it is articulated. We conducted 3 interviews for each company, each lasting between 1.5 and 2 hours. All the interviews 
were taped and transcribed. For each firm, the Founder or the CEO (who were often the same person) and two Project Managers were interviewed by at least two of the researchers. This allowed us to have access to the most knowledgeable person in the firm. In total, the data set represents over 14 hours of interviews and 50 pages of transcript. Most of the data were collected during the interviews and triangulated using data from different respondents. When possible, the data were triangulated also with publicly available sources (e.g., website, press articles) and internal documentation such as project reports and transcripts of meetings. The data analysis process started from the interview transcripts. Each case was analyzed by at least two researchers. Finally, we built a data matrix (cases vs. dimensions, interpreted as the phases of the brokering process) as recommended by Miles and Huberman (1994). The transcripts and the matrix (across cases) were analyzed iteratively and separately by the authors. Across cases we looked and found regularities and patterns, which led us to our understanding of the anatomy of the knowledge brokering process in the two virtual knowledge brokers that we analysed. Of course it is not possible to statistically generalize results from an exploratory case study analysis (Yin, 2003). Our aim is to make analytical and theoretical generalizations to the existing body of knowledge regarding brokering process followed by virtual knowledge brokers. It is our intent that the findings will inform future theoretical and empirical studies regarding the brokering process of virtual knowledge brokers, but we recognize that they cannot be generalized to populations of firms or markets.

\section{RESULTS}

The rich empirical evidence collected through the case studies is structured along the four dimensions of the reference framework presented in section 3. This enables us to answer our two research questions, i.e. (i) providing a description of the brokering process followed by virtual knowledge brokers (section 5.1) and (ii) identifying the main differences between traditional and virtual knowledge brokers as it regards the brokering process they adopt (section 5.2).

\subsection{The brokering process of virtual knowledge brokers}

The empirical evidence collected through the case studies is mapped along the dimensions of our reference framework in Table 3. 
It is possible to identify a common pattern in the brokering processes followed by the two virtual knowledge brokers in our sample. The process is started by the virtual knowledge brokers disclosing the innovation needs of its clients, such as the creation of a logo, the design of a communication campaign, or the development of concept for a new product or service, to a large and diversified community of solvers active all over the world. For instance, Firm A is able to access a community of more than 35,000 solvers coming from 162 different countries. In this way, the virtual knowledge brokers make their clients access different knowledge domains, by directly connecting them with different solvers with very heterogeneous professional backgrounds and experiences. In the access phase, the more diversity there is, the higher the likelihood for the clients to identify an unexpected solution that fits with their needs.

In the learning phase the brief represents the main vehicle of knowledge between seeker and solvers. The client communicates with the community of solvers through a structured brief that contains all the information required to make the solvers understand the clients' innovation problems. Writing a good brief plays a fundamental role in attracting high quality solutions, as suggested by the cofounder of Firm B.

"Clients and solvers cannot communicate until the end of the competition, hence it is fundamental to write a good brief in order to attract high quality solutions. It should include all the information the solvers need to develop a solution"

Co-founder of Firm B

Therefore, both the virtual knowledge brokers in our sample pay particular attention in supporting their clients writing a good brief. For instance, Firm A has developed an ad hoc manual to support its clients in this critical phase of the brokering process. More in detail, this manual includes eight different sections:

1. Description of the client, i.e. who has written the brief;

2. Project Objective / Description, i.e. what the client is looking for;

3. Target Audience, i.e. who will be addressed by the innovation;

4. Proposition, i.e. what the client wants the target audience will understand / perceive / do;

5. Support, i.e. why the target audience should believe in the client's proposition;

6. Character, i.e. what are the features that define the personality of the target audience;

7. Media Plan / Placement, i.e. where the innovation will appear; 
8. Additional Information, i.e. any other information the client wants to share with the solvers.

During the linking phase solvers look at the different briefs disseminated through the platform of the virtual knowledge brokers and decide on which they want to work. Usually the solvers are not allowed to collaborate among them and to build on the solutions of the other solvers. Therefore, they build their solutions mostly relying on their past experience. Once the client has received all the solutions proposed by the solvers, it has to screen them and select the best one (or the best ones). The screening process is a particularly relevant task within the brokering process implemented by virtual knowledge brokers, as suggested by the CEO of Firm A.

\begin{abstract}
"Our clients have to pay particular attention to screen the solutions they receive even if it is a time consuming task. Indeed we can deliver to them even the most creative and innovative solutions that satisfy their needs. However, if they are not able to recognize them, our clients will achieve no benefits from the collaboration"
\end{abstract}

CEO of Firm A

In order to cope with this issue, virtual knowledge brokers usually support their clients in the screening process. For instance, Firm B offers two main alternatives to support the screening process. On the one hand, the virtual knowledge brokers identifies for its clients a short list including the 30 best solutions from which the clients will select the best one. This should allow the clients to focus their attention only on the most promising solutions. On the other hand, Firm B can support the clients in creating a jury that will evaluate and rate each solution received. Both the solutions allow the clients to follow a selection process that is very different from the one they traditionally employ to screen ideas for new products and services developed internally.

Once the clients choose the best solutions, the brokering process ends. Virtual knowledge brokers do not support the implementation of the winning solutions, even if the winning solver and the clients can continue the collaboration.

\title{
5.2 Differences between the brokering process of traditional and virtual knowledge brokers
}

Although the brokering process of traditional and virtual knowledge brokers go through the same macro-phases, i.e. access, learning, linking and implementation, there are some important differences between them that need to be highlighted. 


\section{Access}

The existing literature about traditional knowledge brokers recognizes the important role played by having access to different knowledge domains (Hargadon, 1998; Hargadon and Sutton, 1997), in order to spur innovation as the recombination of existing pieces of knowledge. Access to a variety of knowledge domains is deemed as particularly relevant also for virtual knowledge brokers and a very diverse and heterogeneous community of solvers is one of the main assets of virtual knowledge brokers. However, virtual knowledge brokers access heterogeneous knowledge domains in a different way compared with traditional knowledge brokers. While the latter collaborate with firms working in different industries, absorbing in this way knowledge from different sectors, the former leverages on the opportunities provided by the web in order to involve people from all over the world with different backgrounds and expertise.

“We (Firm A) have about 32,000 registered solvers coming from 162 different countries. The solvers can be clustered in 4 different groups: $16 \%$ creative agencies, $47 \%$ employees of creative agencies, $29 \%$ freelancers, $8 \%$ students. None of the existing intermediaries can pick up knowledge from such a variety of domains. This is particularly important for us"

\section{CEO of Firm A}

Therefore, virtual knowledge brokers have a stronger ability to access different knowledge domains. Put differently, they have stronger structural autonomy, i.e. "relationships free of structural holes at their own end and rich in structural holes at the other end" (Burt, 1992: 45) than traditional knowledge brokers. Indeed, thanks to the use of web technologies, virtual knowledge brokers can reach virtually every node in a knowledge network.

\section{Learning}

Existing research describes the learning phase as one of the most important in the knowledge brokering process (Hargadon, 1998; Hargadon and Sutton, 1997; Colombo et al., 2011). More in details, during this phase traditional knowledge brokers have to learn quickly about their clients' 
needs, develop knowledge on the solutions already existing that can fulfil the clients' needs, and learn from every potentially interesting knowledge domain in order to develop a highly innovative solution. Instead, the learning phase for virtual knowledge brokers have some peculiarities and differences. Virtual knowledge brokers do not perform research or benchmarking activities to learn about existing solutions that fulfil the clients' needs, because they do not address the clients' needs by themselves. They simply broadcast the problem to a large community of solvers and leave them free to learn or not about already existing solutions. This explains why virtual knowledge brokers pay particular attention in communicating the clients' needs to their community of solvers through a structured brief, because this is the only mean for the solvers to learn about the clients' problems.

\section{Linking}

Existing research describes the linking process implemented by knowledge brokers as based on analogy. "Analogies highlight non obvious similarities between two things that appear to be dissimilar, and analogic thinking occurs when an individual, facing a novel problem, see non-obvious similarities in other problems he or she has faced in the past" (Hargadon, 1998: 219). Furthermore knowledge brokers try to foster analogic thinking by favouring communications between different project teams with heterogeneous expertise. For instance, Colombo et al. (2011) describe how a leading knowledge broker manages idea exchanges among different project teams.

Also for virtual knowledge brokers, the process of analogical thinking of their solvers plays an important role in generating innovations, as suggested by the co-founder of Firm B.

"We pay particular attention to involve an highly diversified community of solvers. The more diversity there is, the higher the likelihood to find different promising ways to address the same innovation problems that will give the rise to highly innovative solutions coming from unexpected knowledge domains"

Co-founder of Firm B

However, the process followed by virtual knowledge brokers can represent a barrier to rich analogic thinking of the solvers, because they are not allowed to communicate with each other. As a result, the analogic thinking process cannot rely on the beneficial effect deriving from the exchange of information and ideas among solvers. 


\section{Implementation}

As previously mentioned, traditional knowledge brokers use to realize preliminary embodiments of the final products and services (e.g., sketches, storyboards, prototypes) since the initial stage of the innovation project. By doing so, they are able to concretize the knowledge developed during the previous activities. In order to continually generate new knowledge throughout the innovation process. On the contrary, virtual knowledge brokers leave the implementation of the solutions they collect from the solvers to their clients. In other words, the collaboration between virtual knowledge brokers and their clients end when the clients select the best solution developed by the community of solvers. In order to improve their performance in access, learning and linking virtual knowledge brokers use to track the results of the collaborations even if they do not have an active role in it.

Table 4 gives a synthetic view of the differences between the brokering process followed by traditional and virtual knowledge brokers.

\section{Insert Table 4 here}

\section{DISCUSSION}

As described in innovation research, the way in which knowledge brokers go through the brokering process has a strong impact on their ability to solve different types of innovation problems (Hargadon, 1998; Hargadon and Sutton, 1997; Colombo et al., 2011). Since traditional knowledge brokers and virtual knowledge brokers show some important differences in their brokering processes, managers with responsibilities for innovation in client firms should carefully consider the characteristics of the innovation problem they need to solve to choose the most appropriate type of broker.

In particular, in this paper we have highlighted that virtual knowledge brokers guarantee to their clients access to a wider set of knowledge domains, thanks to the use of internet. On the contrary, due to the peculiarity of the learning phase, it is difficult for these intermediaries to transfer tacit knowledge from their clients to the community of solvers. Indeed communications and physicals interactions among the clients and the solvers are normally absent. The brief is indeed the only communication channel between clients and solvers. Furthermore, virtual knowledge brokers are less suitable to leverage the analogic thinking of their solvers, since solvers cannot usually communicate 
among them, exchanging their points of view and building their solutions on the knowledge of each other.

Therefore, it appears that virtual knowledge brokers are suitable partners when access to many diverse knowledge domains is more important than developing a deep knowledge of the needs of the clients or more important than producing unconventional combinations of existing knowledge. In other words, virtual knowledge brokers seem more suitable to solve simple ideation problems, such as logo creation, or to provide fresh ideas for new products, where it is important to identify many alternative solutions in short time and from unknown knowledge domains, rather than solve complex problems such as envisioning new scenarios or develop working concept of new products.

This interpretation is supported by the words of the co-founder of Firm B.

"For complex problems, such as the design of a new innovative video camera we adapt our process. In a first phase we run a competition and we select the most promising 10 ideas. Then we invite the solvers of these ten solutions to collaborate directly with our client in order to better understand its needs and leverage their different experiences to design together one highly innovative product"

Co-founder of Firm B

\section{CONCLUSION}

Virtual knowledge brokers provide their clients with an important service that can help them solve challenging problems along the NPD process. However, despite the increasing importance of the phenomenon, no efforts have been done so far to investigate how this new class of intermediaries deliver its brokering service. This paper analyses how virtual knowledge brokers go through the four macro-phases of the brokering process, i.e. access, learning, linking and implementation to deliver value for their clients. Furthermore, the paper underlines the main differences between the process followed by traditional and virtual knowledge brokers. In particular, virtual knowledge brokers, thanks to the use of internet technologies, seem to have a superior ability in accessing different knowledge domains, compared with traditional knowledge brokers. On the contrary, virtual knowledge brokers are likely to be less effective in the learning and linking phases of the brokering process. Regarding the learning phase, virtual knowledge brokers do not address directly the innovation problem of their clients but they broadcast it to a large community of potential solvers in 
order to identify unexpected solutions. Therefore, compared to traditional knowledge brokers, virtual ones do not perform research or benchmarking activities to learn about existing solutions that fulfil the clients' needs. Regarding the linking phase, the process followed by virtual knowledge brokers can hinder analogical thinking of the solvers because they are not allowed to communicate with each other and to exchange ideas and experiences.

The paper is rich of both theoretical and managerial implications. From a theoretical point of view, the paper is one the first attempt to explore in more detail the brokering process followed by virtual knowledge brokers and it complements existing literature on the topic, which has mostly analysed the effect of the superior ability of virtual knowledge brokers in accessing different and dispersed knowledge domains. More in detail, it suggests some interesting avenues for future theoretical and empirical research into virtual knowledge brokers. First, our study shows that a weakness in the brokering process of virtual knowledge brokers lies in the difficulty for the solvers to learn in details the innovation problems of the clients without a direct relationship between them. Besides the use of a properly constructed brief, is there any other activity or service that a virtual knowledge broker can offer to address this relevant cognitive problem? Second, our case studies show that virtual knowledge brokers do not allow interaction between the solvers and this might hinder analogical thinking, which is key in the linking phase of the brokering process. Again, an interesting suggestion for future research is to investigate what opportunities exist for virtual knowledge brokers to allow solvers active in any part of the world to collaborate, share ideas and experiences and improve the performance of the linking phase of the process. For instance, can virtual collaborative environments represent a solution to this need? Form a managerial perspective, the paper suggests first that virtual and traditional knowledge brokers are suited to solve different types of innovation problems, and this has implications for managers working in firms that have to choose the broker with which to collaborate in solving an innovation need. Second, from the understanding of the anatomy of the brokering process followed by virtual brokers, the papers gives some suggestions to those managers who decide to work with this type of intermediary. The size and heterogeneity of the network of solvers make the difference in the success of the virtual brokering process. Therefore, it is of great importance to analyse the characteristics of the network of solvers to which a broker gives access and consider it a critical criterion for selecting with which broker start working. Moreover, the paper suggests to managers in the client firms to give special attention to writing a good brief of their innovation problem, as this is the only tool that most virtual brokers offer to enable learning on the side of the solvers. Writing a good brief is a task that requires a certain deal of experience, therefore the suggestion to managers is to experiment with writing briefs before relying on a broker to solve an important innovation problem and follow closely the indications of the broker itself. Finally, it is of 
paramount important to devote enough time and resources to the screening of the proposals coming from the network of solvers. Especially if the brief is well written and the innovation problem is interesting, it is likely that the client firm will receive a low of suggestions about how the problem should be solved. If the client firm does not have some level of prior knowledge on the topic (which is known as absorptive capacity in management research, see Cohen and Levinthal, 1990) and devote enough effort to the screening activity, the risk is high that it does not capture the maximum value from using the virtual knowledge broker.

However, the paper has several limitations that open the avenue for further research. First, because the paper is based on case studies and it is exploratory in its intent, it is not possible to generalize results to all virtual knowledge brokers. Hence, further studies based on larger samples and involving virtual knowledge brokers working in different fields represent an interesting area to explore. Second, discussion about the link between the typology of intermediary, i.e. traditional or virtual, and the ability of each typology to solve different kinds of innovation problems need to be subject or further empirical analyses, using larger and representative samples of knowledge brokers and client firms. However, we believe that our findings can foster future theoretical and empirical studies on the topic. 


\section{REFERENCES}

Ahuja G. (2000). Collaboration networks, structural holes, and innovation: A longitudinal study, Administrative Science Quarterly, Vol. 45, No. 3, pp. 425-455.

Bolisani E and Scarso E. (2009). The role of KIBS in the technological renovation of local economies. Evidence from the computer services sector, International Journal of Entrepreneurship and Innovation Management, Vol. 9, No. 1/2, pp. 29-46.

Boudreau K, Lacetera N and Lakhani K. (2011). Incentives and Problem Uncertainty in Innovation Contests: An Empirical Analysis, Management Science, Vol. 57, No. 5, pp. 843-863.

Burt RS. (1992). Structural Holes: The Social Structure of Competition, Harvard University Press, Cambridge, MA.

Chesbrough H. (2006). Open Business Models: How to Thrive in the New Innovation Landscape, Harvard Business School Publishing, Cambridge, MA.

Chiaroni D, Chiesa V, De Massis A and Frattini F. (2008). The knowledge bridging role of technical and scientific services in knowledge-intensive industries, International Journal of Technology Management, Vol. 41, No. 3/4, pp. 249-272.

Cohen WM and Levinthal DA. (1990). Absorptive capacity: A new perspective on learning and innovation, Administrative Science Quarterly, Vol. 35, No. 1, pp. 128-152.

Colombo G, Dell'Era C and Frattini F. (2011). New Product Development (NPD) Service Suppliers in Open Innovation Practices: Processes and Organization for Knowledge Exchange and Integration, International Journal of Innovation Management, Vol. 15, No. 1, pp. 165-204.

Colombo G, Dell'Era C and Frattini F. (2015). Exploring the Contribution of Innovation Intermediaries to the New Product Development (NPD) Process: a Typology and an Empirical Study, R\&D Management, forthcoming, ISSN: 0033-6807. DOI 10.1111/radm.12056.

Colombo G, Klanner IM, Roiser S and Buganza T. (2013). Crowdsourcing intermediaries and problem typologies: an explorative study, International Journal of Innovation Management, Vol. 17, Issue 2, DOI: $10.1142 / \mathrm{S} 1363919613500059$.

Cooper RG and Kleinschmidt EJ. (2003). Benchmarking the Firm's Critical Success Factors in New Product Development, Journal of Product Innovation Management, Vol. 12 No. 5, pp. 374-391.

Dell'Era C, Landoni Pand Verganti R. (2015). "From creative individuals to creative capital: value creation and appropriation strategies of creative knowledge-intensive business services, International Journal of Innovation Management, Vol. 19, No. 1.

Doloureux D and Muller E. (2007). The key dimensions of knowledge-intensive business services (KIBS) analysis. A decade of evolution, Working Paper Firms and Regions No. U1/2007, Fraunhofer-Institute fur System-und Innovationsforschung-ISI, Karlshrue.

Dubois A and Gadde LE. (2002). Systematic combining: An abductive approach to case research. Journal of Business Research, Vol. 55, pp. 553-560.

Easton G. (1998). Case research as a methodology for industrial networks: A realist apologia. In Naude P and Turnbull P. (Eds.). Network dynamics in international marketing. Oxford: Pergamon.

Eisenhardt KM and Graebner ME. (2007). Theory building from cases: opportunities and challenges, Academy of Management Journal, Vol. 50, No. 1, pp. 25-32.

Grant RM. (1996). Toward a knowledge-based theory of the firm, Strategic Management Journal, Vol. 17, pp. 109-122.

Gulati R. (1998). Alliances and Network, Strategic Management Journal, Vol. 19, No. 4, pp. 293-317.

Hargadon AB. (1998). Firms as knowledge brokers: lessons in pursuing continuous innovation, California Management Review, Vol. 40, No. 3, pp. 209-227. 
Hargadon AB and Sutton RI. (1997). Technology brokering and innovation in a product development firm, Administrative Science Quarterly, Vol. 42, No. 4, pp. 716-749.

Hargadon A and Sutton R. (2000). Building an innovation factory, Harvard Business Review, Vol. 78, No. 3, pp. 157-166.

Haunschild P and Sullivan B. (2002). Learning from complexity: Effects of prior accidents and incidents on airlines' learning, Administrative Science Quarterly, Vol. 47, No. 4, pp. 609-643.

Henderson RM and Clark KB. (1990). Architectural innovation: The Reconfiguration of Existing Product Technologies and the Failure of Established Firms, Administrative Sciences Quarterly, Vol. 35, No. 4, pp. 930.

Howells J. (2006). Intermediation and the role of intermediaries in innovation, Research Policy, Vol. 35, No. 5, pp. 715-728.

Jeppesen LB and Lakhani KR. (2010). Marginality and Problem-Solving Effectiveness in Broadcast Search, Organization Science, Vol. 21, No. 5, pp. 1016-1033.

Kogut B and Zander U. (1992). Knowledge of the firm, combinative capabilities, and the replication of technology, Organization Science, Vol. 3, No. 3, pp. 383-397.

Miles MB and Huberman AM. (1994). Qualitative Data Analysis: an expanded sourcebook, Sage, Thousand Oaks, CA.

Muhdi L, Daiber M, Friesike S and Boutellier R. (2011). The crowdsourcing process: an intermediary mediated idea generation approach in the early phase of innovation, International Journal of Entrepreneurship and Innovation Management, Vol. 14, No.4, pp. 315-332.

Nielsen KE, Basalisco B and Thelle MH (2013). The impact of online intermediaries on the EU economy. Copenhagen Economics.

Rodan S and Galunic C. (2004). More than network structure: how knowledge heterogeneity influences managerial performances and innovativeness, Strategic Management Journal, Vol. 25, No. 6, pp. 541-562.

Siggelkow N. (2007). Persuasion with case studies. Academy of Management Journal, Vol. 50, No. 1, pp. 2024.

Sutton R. (2002). Weird ideas that spark innovation, Sloan Management Review, Vol. 43, No. 2, pp. 83-87.

Terwiesch $\mathrm{C}$ and $\mathrm{Xu}$ Y. (2008). Innovation contests, open innovation, and multiagent problem solving, Management Science, Vol. 54, No. 9, pp. 1529-1543.

Tran Y, Hsuan J and Mahnke V. (2011). How do innovation intermediaries add value? Insight from new product development in fashion markets, $R \& D$ Management, Vol. 41, No. 1, pp. 80-91.

Verona G, Prandelli E and Sawhney M. (2006). Innovation and Virtual Environments: Towards Virtual Knowledge Brokers, Organization Studies, Vol. 27, No. 6, pp. 765-788.

Wood PA, Byson J and Keeble D. (1993). Regional patterns of small firm development in the business services: evidence from the UK, Environment and Planning A, Vol. 25, No. 5, pp. 677-700.

Yin RK. (2003). Case study research: design and methods. London: Sage. 